\title{
The effect of mouthwash containing chlorhexidine digluconate $0.2 \%$ on halitosis in smokers and non-smokers
}

\author{
Galina Gavazova and Petia Pechalova* \\ Department of Oral Surgery, Faculty of Dental Medicine, Medical University of Plovdiv, Bulgaria
}

\begin{abstract}
Background: Halitosis is a term used to describe bad or unpleasant odours from the oral cavity. The aim of this study is to investigate halitosis after administration of mouthwash containing chlorhexidine digluconate $0.2 \%$ (Parodontax, GlaxoSmithKline, GB).

Material and methods: The study included 60 dental patients, 30 smokers and 30 non-smokers, all clinically healthy, who had not used mouthwash containing chlorhexidine digluconate $0.2 \%$ for the past 6 months. The patients were instructed to rinse their oral cavity with the supplied mouthwash twice daily for a 14 -day period and to maintain oral hygiene as usual. The rinsing technique involved swishing with $10 \mathrm{~mL}$ of chlorohexidine digluconate $0.2 \%$ twice, successively, for 1 minute. After rinsing, the mouth was not flushed. Halitosis of the air exhaled from the oral cavity was measured using FitScan Breath Checker HC-212SF (Tanita Corporation, USA) during normal breathing, in the morning, on an empty stomach, without oral cavity toilette - before the start of the study and on day 14 from the start of administration of mouthwash containing chlorhexidine digluconate $0.2 \%$.

Results: There was no statistically significant difference between the two sexes in terms of age $(p=0.392)$. There was no statistically significant difference in halitosis levels between smokers $v$ s. non-smokers ( $p=0.07)$. In terms of sex distribution of smokers, $15(39.5 \%)$ of the female subjects and 15 (68.2\%) of the male subjects used tobacco products. A statistically significant difference was found between the two sexes in terms of smoking ( $p=0.032$ ). Fourteen-day administration of Parodontax resulted in a statistically significant decrease in halitosis levels in the subjects studied $-2.1 \pm 1.15$, $p<0.0001$. This trend persisted in both smokers (the mean halitosis level after a 14-day period of administration of Parodontax was $2.27 \pm 0.21, \mathrm{p}=0.006$ ) and non-smokers (the mean halitosis level after a 14-day period of administration of Parodontax was $1.93 \pm 0.21, \mathrm{p}<0.0001)$.
\end{abstract}

Conclusion: Our study showed that 14-day administration of Parodontax resulted in a statistically significant decrease in halitosis levels in both smokers and nonsmokers.

\section{Introduction}

Halitosis is a term used to describe bad or unpleasant odours from the oral cavity. The term "halitosis" is derived from the Latin word "halitus", which means "breath", and the Greek suffix "-osis" which describes a pathological process [1]. Halitosis gases are mainly volatile sulphur compounds (VSCs). These gases include hydrogen sulphide, methyl mercaptan and dimethyl sulphide. Not only VSCs play a role in the development of halitosis. Volatile aromatic compounds such as indole, skatole, organic acids (acetic acid, propionic acid) and amines (cadaverine and putrescine) also play a role in the development of halitosis. The production of VSCs in the oral cavity and the onset of halitosis depend on the amount of saliva, decreased oxygen concentration in the oral cavity, bacterial reproduction and metabolism [2]. The prevalence of halitosis in the general population varies in different studies - 2\% (Soder B), 27.5\% (Miyazaki H) [3], 50\% (Nachnani S). According to the literature, the prevalence of halitosis in children is between 5\% and 75\% (Karbanda OP, Polanco C).

The aim of this study is to investigate halitosis after administration of mouthwash containing chlorhexidine digluconate $0.2 \%$ (Parodontax, GlaxoSmithKline, GB).

\section{Material and methods}

The study included 60 dental patients, 30 smokers and 30 non-smokers, all clinically healthy, who had not used mouthwash containing chlorhexidine digluconate $0.2 \%$ for the past 6 months. The patients were instructed to rinse their oral cavity with the supplied mouthwash twice daily for a 14-day period and to maintain oral hygiene as usual. The rinsing technique involved swishing with $10 \mathrm{~mL}$ of chlorohexidine digluconate $0.2 \%$ twice, successively, for 1 minute. After rinsing, the mouth was not flushed. Halitosis of the air exhaled from the oral cavity was measured using FitScan Breath Checker HC212SF (Tanita Corporation, USA) during normal breathing, in the morning, on an empty stomach, without oral cavity toilette - before the start of the study and on day 14 from the start of administration of mouthwash containing chlorhexidine digluconate $0.2 \%$. The abovementioned portable device measures the amount of volatile sulphides and hydrocarbons responsible for the malodor of the air exhaled from the mouth, and the results are displayed in six levels (Figure 1).

\section{Results}

The study included 38 females (63.3\%) and 22 males (36.7\%). The mean age of the participants was $28.85 \pm 10.63$ years. The mean age

${ }^{\star}$ Correspondence to: Petia Pechalova, Department of Oral Surgery, Faculty of Dental Medicine, Medical University of Plovdiv, Bulgaria, Tel: 0359898468498; E-mail: pechalova@abv.bg

Key words: halitosis levels, chlorhexidine digluconate, portable device

Received: December 05, 2019; Accepted: December 27, 2019; Published: December 31, 2019 
Table 1. Halitosis levels before and after administration of Parodontax

\begin{tabular}{|c|c|c|c|c|c|c|c|}
\hline \multirow{2}{*}{$\begin{array}{c}\text { Cohort } \\
\text { Halitosis }\end{array}$} & Total & $\begin{array}{c}\text { Non-smokers } \\
\mathrm{n}=23\end{array}$ & $\begin{array}{c}\text { Smokers } \\
\mathrm{n}=15\end{array}$ & Total & $\begin{array}{c}\text { Non-smokers } \\
\mathrm{n}=7\end{array}$ & $\begin{array}{c}\text { Smokers } \\
\mathrm{n}=15\end{array}$ & $\begin{array}{c}\text { Non-smokers } \\
\mathrm{n}=30\end{array}$ \\
\hline $\begin{array}{c}\text { Before the } \\
\text { administration of } \\
\text { Parodontax }\end{array}$ & $3.92 \pm 0.12$ & $3.83 \pm 0.18$ & $4.07 \pm 0.12$ & $3.91 \pm 0.19$ & $3.43 \pm 0.43$ & $4.13 \pm 0.17$ \\
\hline $\begin{array}{c}\text { After a 14- } \\
\text { day period of } \\
\text { administration of } \\
\text { Parodontax }\end{array}$ & $2.1 \pm 1.15$ & $2.09 \pm 0.22$ & $2.2 \pm 0.24$ & $2.05 \pm 0.3$ & $1.43 \pm 0.53$ & $2.33 \pm 0.36$ \\
\hline
\end{tabular}

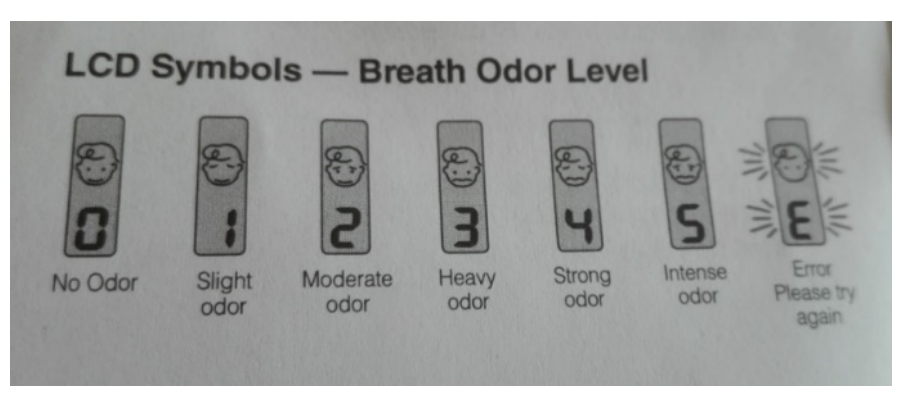

Figure 1. Halitosis levels measured with FitScan Breath Checker HC-212SF (Tanita Corporation, USA) in accordance with manufacturer's instructions

of the female subjects was $27.95 \pm 1.79$ years, and that of the male subjects was $30.41 \pm 2.13$ years. There was no statistically significant difference between the two sexes in terms of age $(p=0.392)$. In terms of sex distribution of smokers, $15(39.5 \%)$ of the female subjects and $15(68.2 \%)$ of the male subjects used tobacco products. A statistically significant difference was found between the two sexes in terms of smoking $(p=0.032)$. For smokers, the mean number of cigarettes a day was $7.53 \pm 1.15$. Female smokers smoked an average of $4.82 \pm 1.09$ cigarettes a day, while male smokers reported an average of $12.23 \pm 2.2$ cigarettes a day. There was a statistically significant difference between the two sexes in terms of the number of cigarettes a day $(p<0.0001)$.

The levels of halitosis in the subjects included in the study are presented in table 1.

The assessment of halitosis found a mean level of $3.92 \pm 0.79$ in the subjects studied. The mean level was $3.92 \pm 0.12$ and $3.91 \pm 0.19$ in females and males, respectively. There was no statistically significant difference between the two sexes in terms of halitosis levels. The study found that in non-smokers the mean halitosis level was $3.73 \pm 0.17$, while in smokers it was higher $-4.1 \pm 0.1$. There was no statistically significant difference in halitosis levels between smokers $v s$. nonsmokers $(\mathrm{p}=0.07)$.

The study found that age was not a factor influencing halitosis. No correlation was found between halitosis levels and the age of the subjects included in the study, both before the start of Parodontax treatment $(\mathrm{r}$ $=-0.62, p=0.637)$ and after a 14-day period of administration of this treatment $(\mathrm{r}=-0.121, \mathrm{p}=0.357)$.

It was found that 14-day administration of Parodontax resulted in a statistically significant decrease in halitosis levels in the subjects studied $-2.1 \pm 1.15, \mathrm{p}<0.0001$. This trend persisted in both smokers (the mean halitosis level after a 14-day period of administration of Parodontax was $2.27 \pm 0.21, \mathrm{p}=0.006$ ) and non-smokers (the mean halitosis level after a 14-day period of administration of Parodontax was $1.93 \pm 0.21, \mathrm{p}<0.0001)$.

The assessment of halitosis levels, which were measured twice, found that they were evenly distributed. A statistically significant
Pearson correlation coefficient was found between halitosis levels prior to initiation of rinsing with Parodontax and 14 days later $-\mathrm{r}=0.473, \mathrm{p}$ $<0.0001$. No statistically significant Pearson correlation coefficient was found between halitosis levels before and after the end of Parodontax treatment in non-smokers $(\mathrm{r}=0.235, \mathrm{p}=0.007) v s$. smokers $(\mathrm{r}=0.145$, $\mathrm{p}=0.27)$.

\section{Discussion}

Our study showed that the two-week administration of chlorhexidine-based mouthwash resulted in a statistically significant reduction in halitosis levels in the subjects studied. Results similar to ours were obtained by Rosenberg et al. who found that rinsing with $0.2 \%$ CHX resulted in a $43 \%$ reduction in the levels of VSCs and a $50 \%$ reduction in organoleptic ratings on a one-day basis, which in turn resulted in a lower level of halitosis. In contrast, Ah-Reum Shin et al. [4] conducted a study of halitosis involving 20 female participants who had not taken any medication and had not smoked for the past 6 months; no statistically significant difference before and after rinsing the mouth with mouthwash containing chlorhexidine digluconate was found $(P>0.05)$.

We found no statistically significant difference between both sexes in terms of halitosis levels. Contrary to our results, Liu et al. [5], who studied the prevalence of halitosis in the Chinese population, found that the levels of volatile sulfur compounds (VSCs) in the air exhaled from the mouth was significantly lower in males. In addition, we found that age was not a factor influencing halitosis. Our results are supported by a study conducted by Miyazaki et al. [3] involving 2,672 individuals between 18 and 64 years of age, which found that there were no significant differences in the levels of VSCs between males and females in all age groups. According to this study, age is not a factor for increasing halitosis levels.

Our data shows that the use of chlorhexidine-containing mouthwash results in reduction in halitosis levels in both smokers and non-smokers. Jiun et al. [6] examined the association between smoking, together with poor oral hygiene status, and halitosis in a comparative study of 100 smokers and 100 non-smokers aged 18-50 years in Malaysia and found significantly higher levels of halitosis and worse oral hygiene in smokers than in non-smokers. A study by Rad et al. [7] examined the salivary flow rate in 100 smokers and 100 non-smokers and found that long-term smoking was associated with a significant reduction in the amount of saliva, which is one of the factors that cause halitosis. Mendez L. et al. [8] confirmed that the use of mouthwashes containing chlorhexidine digluconate results in a decrease in the amount of volatile sulphur compounds in the oral cavity. Similar results were obtained by van Steenberghe D et al. [9] who found a decrease in halitosis levels and the oral microbial load on the dorsal surface of the tongue and in the saliva due to the use of mouthwashes containing chlorhexidine digluconate, although there was no effect on the composition of the microflora in the oral cavity. 
The study of Winkel EG et al. [10] confirmed that chlorhexidinecontaining mouthwash is effective for the treatment of oral halitosis. Setia et al. [11] conducted a study in 277 dental students. Of these, 200 were females and 77 were males. All participants reported that they regularly brushed their teeth. $2.5 \%$ of female subjects and $6.5 \%$ of male subjects in the study were smokers, and halitosis was found in $80 \%$. The authors found a statistically significant correlation between smoking and halitosis. They concluded that females maintain better oral hygiene and, therefore, are less likely to have halitosis. Contrary to these results, in terms of both characteristics - sex and smoking - we found no statistically significant difference in halitosis levels. Khaira $\mathrm{N}$ et al. [12] conducted a study to test the hypothesis that the synthesis of toxic volatile sulphur compounds could be increased as a result of smoking. They measured the levels of VSCs in 12 smokers and 11 non-smokers using a portable sulphide monitor. They also determined anaerobic and aerobic counts of the total cultivable subgingival microflora in both groups. They found that the percentage of sites with high sulphide levels (greater than or equal to 10 units) detected in moderate $(4-6 \mathrm{~mm})$ and deep $(\geq 7 \mathrm{~mm})$ periodontal pockets was significantly higher in smokers compared to non-smokers ( $\mathrm{P}=0.040$ and $\mathrm{P}=0.005$, respectively). The authors did not find any significant difference in the microbiological parameters studied between the two groups. Based on their results, they concluded that the increased production of volatile sulphur compounds is an additional mechanism for the increased propensity for developing periodontitis in smokers and explained the relationship between smoking and halitosis.

\section{Conclusion}

Our study showed that 14-day administration of Parodontax resulted in a statistically significant decrease in halitosis levels in both smokers and non-smokers.

\section{References}

1. Akcan AB, Boz AB, Oygucu SE, Turhan M, Dinc O (2008) Halitosis. New J Med 25: 134-137.

2. Aylikci BU, Colak H (2013) Halitosis: From diagnosis to management. J Nat Sci Biol Med 4: 14-123. [Crossref]

3. Miyazaki H, Sakao S, Katoh Y, Takehara T (1995) Correlation between volatile sulphur compounds and certain oral health measurements in the general population. $J$ Periodontol 66: 679-684. [Crossref]

4. Shin Ah, Seoul-Hee N (2018) The effects of various mouthwashes on the oral environment change for oral health care. Biomed Res 29: 1724-1729.

5. Liu XN, Shinada K, Chen XC, Zhang BX, Yaegaki K, et al. (2006) Oral malodorrelated parameters in the Chinese general population. J Clin Periodontol 33: 31-36.

6. Jiun IL, Siddik SN, Malik SN, Tin-Oo MM, Alam MK, et al. (2015) Association Between Oral Hygiene Status and Halitosis Among Smokers and Nonsmokers. Oral Health Prev Dent 13: 395-405. [Crossref]

7. Rad M, Kakoie S, Niliye Brojeni F, Pourdamghan N (2010) Effect of Long-term Smoking on Whole-mouth Salivary Flow Rate and Oral Health. J Dent Res Dent Clin Dent Prospects 4: 110-114. [Crossref]

8. Mendes L, Coimbra J, Pereira AL, Resende M, Pinto MG (2016) Comparative effect of a new mouthrinse containing chlorhexidine, triclosan and zinc on volatile sulphur compounds: a randomized, crossover, double-blind study. Int J Dent Hyg 14: 202-208. [Crossref]

9. Van Steenberghe D, Avontroodt P, Peeters W, Pauwels M, Coucke W, et al. (2001) Effect of different mouthrinses on morning breath. J Periodontol 72: 1183-1191. [Crossref]

10. Winkel EG, Roldán S, Van Winkelhoff AJ, Herrera D, Sanz M (2003) Clinical effects of a new mouthrinse containing chlorhexidine, cetylpyridinium chloride and zinclactate on oral halitosis. A dual-center, double-blind placebo-controlled study. J Clin Periodontol 30: 300-306. [Crossref]

11. Setia S, Pannu P, Gambhir RS, Galhotra V, Ahluwalia P, et al. (2014) Correlation of oral hygiene practices, smoking and oral health conditions with self-perceived halitosis amongst undergraduate dental students. J Nat Sci Biol Med 5: 67-72. [Crossref]

12. Khaira N, Palmer RM, Wilson RF, Scott DA, Wade WG (2000) Production of volatile sulphur compounds in diseased periodontal pockets is significantly increased in smokers. Oral Dis 6: 371-375. [Crossref]

Copyright: (2019 Gavazova G. This is an open-access article distributed under the terms of the Creative Commons Attribution License, which permits unrestricted use, distribution, and reproduction in any medium, provided the original author and source are credited. 